\title{
O PROBLEMA ÉTICO NA EDUCAÇÃO E O USO DA LINGUAGEM
}

\author{
THE ETHICAL PROBLEM IN EDUCATION AND THE USE OF LANGUAGE
}

\author{
Hélcia Macedo de Carvalho Diniz e Silva* \\ Luiz Cláudio Inocêncio**
}

\section{RESUMO}

Neste trabalho o objetivo geral é desenvolver uma reflexão séria sobre o problema ético na educação com base em fundamentos da Filosofia Clássica sobre a ética e as possíveis relações da Filosofia Contemporânea a partir da Ética da linguagem desenvolvida por John Langshaw Austin. Primeiro, não fazemos uma definição de Ética com a amplitude que o tema exige devido à exiguidade de tempo; buscaremos elementos teóricos que nos permitam desenvolver o debate sobre problemáticas educacionais e abordar alguns problemas inerentes à ética na educação e, por fim, apontar possíveis relações entre o uso ético da linguagem e educação. Isso não implica a elaboração de uma proposta que ofereça soluções para essa temática, por não ser possível dizer a última palavra sobre o tema em tela. Trata-se de uma revisão de literatura acerca do tema. Desse cenário sobressai a discussão iniciada no século XXI abordando a ética educacional e a exigência por atitudes éticas que constituem os espaços da academia e da política. Segue a pergunta que se estabelece: como o discurso sobre o ser e o agir humanos, diante do problema ético na educação, pode contribuir para a formação humana?

PALAVRAS-CHAVE: Ética. Educação. Linguagem. Discurso. Problemas na educação.

\begin{abstract}
In this paper, the main objective is to develop a serious reflection about the ethical problem on education, based on fundaments from the Classic Philosophy about the ethic and the possible relations of Contemporary Philosophy from the language's Ethics, developed by John Langshaw Austin (1911-1960). At first, Ethics is not defined with the breadth that the theme demands, it is sought theoretical elements that allows developing the debate about educational problematics and approach some inherent to ethics on education, and, lastly, appoint possible relations between the ethical use of language and education. This does not imply on the elaboration of a purpose that offers solutions to this thematic, thus it is not possible to say the last word about the theme displayed. It is about a literature revision on the theme. From this scenario, protrudes the discussion, initiated in the XXI century, approaching the educational ethics and the demand for ethical attitudes that constitute the spaces of the academy and the politics. Following, the question that establishes: how can the speech about the human being and acting, before the ethical problem on education, contribute to human formation?
\end{abstract}

KEYWORDS: Ethics. Education. Language. Speech. Problems on education.

\footnotetext{
* Doutorado (DF/PUC-Rio). Mestrado (UFPB/2006). Doutorado em Linguística (PROLING/UFPB-2015). Mestrado em Letras (PPGL/2007). Em curso, doutorado em Educação (PPGE-UFPB). Professora do Centro Universitário de João Pessoa (UNIPÊ - Cruzeiro do Sul). E-mail: helciamacedo@ yahoo.com.br.

** Mestre em Filosofia no programa da Universidade Estadual do Oeste do Paraná (UNIOESTE-Campus de Toledo). E-mail: luizclaudioinocencio@hotmail.com
} 


\section{INTRODUÇÃO}

De acordo com o conceito de polifonia, cunhado pelo filósofo e linguista russo Mikhail Bakhtin (1981), em Problemas da poética de Dostoiévski, não há homogeneidade no uso da linguagem, e o discurso se dá a partir da apropriação da palavra alheia. A partir desse entendimento tecemos um debate sobre o problema ético na educação. Devido à amplitude que o tema exige não apresentaremos uma definição de ética para não cair no reducionismo, haja vista a profundidade da questão filosófica; buscaremos bases nos teóricos que nos permitam desenvolver o debate, em seguida teceremos considerações sobre alguns problemas inerentes à ética na educação e apontaremos os pontos de contato, por meio da linguagem, entre ética e educação.

Esta pesquisa, portanto, constrói-se a partir de outras vozes, as quais ressoam em nós e por nós são propagadas por estarem presentes nas ideias aqui desenvolvidas e são apropriadas, quando possível ressignificadas, tornadas inovadoras para o contexto, embora esta não seja a primeira nem será a última palavra. O problema da pesquisa que se estabelece é o seguinte: como o discurso sobre o ser e o agir humanos diante do problema ético na educação contribui para a formação humana?

Tal pergunta reflete uma preocupação presente nos debates desde a modernidade, que teve início entre os séculos XVI e XVII e se estende até hoje. Desde então, o ser humano teve abertura para acumular conhecimentos, desenvolver tecnologias e vários outros tipos de riquezas, principalmente nos países da América do Norte e Europa.

Iniciou-se, portanto, uma corrida ao desenvolvimento por meio do conhecimento e, por conseguinte, o controle do capital provocou uma maior concentração de riquezas em alguns lugares no mundo, causando exclusão e marginalização social, tendo como efeitos para a maioria da população mundial uma realidade de fome, miséria e poluição. Diante dessa realidade, desde o início do século XXI o mundo clama, em todos os níveis, por debates e soluções para os problemas político e educacional, como fontes para iniciar trabalhos que minimizem o sofrimento de muitas pessoas. Desses debates o termo mais difundido é ética. Nos fóruns legítimos de ambientalistas, gestores nos âmbitos público e privado, bem como entre educadores, é consenso o entendimento de que o ser humano precisa mudar de atitude. Quanto ao educador, em seu trabalho de mediação pedagógica, no processo de ensinoaprendizagem, bem como ao estudante em seu protagonismo, é exigida uma postura ética e ainda mais engajamento para construção de processos educacionais, haja vista que a realidade se constrói por meio do diálogo, no qual os sujeitos falantes assumem posturas responsivas- 
ativas (BAKHTIN, 1981). O agir pode ser moral e ético, a depender do âmbito em que os sujeitos se encontram e atuam.

Segundo Vaz (1991), provavelmente a origem dos termos Ética e Moral tenha provocado a dúvida sobre seus significados. Para tanto, é necessário esclarecer acerca da sinonímia original desses termos, tendo sido Hegel (1770-1831) no livro Fenomenologia do espírito (1992) quem propôs esta distinção: o significado kantiano de moral interior é o imperativo categórico que faz o homem fazer o que é universalmente correto. Para o pensamento aristotélico, ética encontra-se no campo social e político do agir do ser humano.

De modo mais amplo, Aristóteles utilizou ética como adjetivo para qualificar um determinado tipo de saber, aquele que se traduz do grego como sendo o exercício constante das virtudes morais e como o exercício de investigação e reflexão metódica sobre os costumes. Não de modo reducionista, para Aristóteles a ética seria a prática da virtude e/ou o estudo acerca dos hábitos e costumes humanos. Com essa breve apresentação, não queremos trazer uma definição de ética, isso porque ela vai muito além dessas palavras; a ética é uma atitude filosófica, ir ao radical do problema, observar a raiz da questão. De fato, ética não é um saber acabado. O ser humano pode escolher entre isso ou aquilo, a escolha decide a sua conduta.

Etimologicamente, moral corresponde ao termo em latim morales. Kant imprime à moral o significado de obediência a regras universais, isto é, é um dever racional comportarse com base na razão, são as maneiras e forma de vida de cada um que definem o ser humano a partir da resposta que é dada diante de um dilema às seguintes perguntas: "O que devo saber? O que devo fazer? O que me é permitido esperar? O que é o homem?” (KANT, 2011, p. 96).

O processo educacional é composto de delimitações que envolvem os agentes da educação. Para enfrentar os problemas é necessário que o educador se posicione, declare o seu entendimento e abra-se aos demais sujeitos pertencentes do processo, a fim de que a vivência em sala de aula seja um espaço criativo, dinâmico e inovador para todos que fazem parte daquele contexto. Exige uma rotina que engloba estudantes e educadores capazes de enfrentar as demandas de um mundo em transformação. De modo racional, o ser humano pode fazer o mundo do seu jeito, porque ele não nasce sabendo, não nasce pronto. O homem é capaz de fazer algo de diversos modos, algumas situações se realizam ao ou por usar a linguagem como sendo um fazer, isso porque o dizer é realizar ações concretas em determinados contextos bem definidos (AUSTIN, 1990). O dizer como fazer é uma atitude 
que deve ser ética, um posicionamento, uma forma de transformar a realidade em que se está vivendo e atuando. São os modos de dizer, como dizer e ao dizer que constituem o sujeito falante. O âmbito educacional não prescinde da linguagem, os agentes da educação expõem seus posicionamentos ao passo que fazem declarações e promessas. Os comportamentos dos seres humanos são frutos de sua liberdade de escolha.

Com os atuais problemas na educação brasileira, os espaços da educação são desafiantes e tensos: falta de infraestrutura, higiene, merenda, material e espaços físicos adequados. De modo amplo, as salas não estão adaptadas às diversas formas de aprendizado (metodologias ativas). Esses problemas refletem questões éticas, porque para escolher é preciso observar valores nas situações.

Nesse sentido, este trabalho trata do fenômeno ético em duas perspectivas: ética clássica e ética na filosofia contemporânea. Este último fenômeno à luz da Ética da alteridade segundo Austin (1990), pensador que pode contribuir para a construção desta pesquisa sobre a eticidade da educação.

Para além dessa perspectiva, apresentamos o pensamento de Bakhtin sobre o conceito de dialogismo, cuja essência é a ética no discurso, a própria essência da linguagem, igualmente denominada de relações dialógicas, significando: "a língua em sua integridade concreta e viva e não a língua como objeto específico da linguística, obtido por meio de uma abstração absolutamente necessária de alguns aspectos da vida concreta do discurso" (BAKHTIN, 2006, p. 207). A linguagem, quanto mais adequada ao contexto e às pessoas envolvidas no processo, mais favorece a atitude ética.

Na pragmática, dizer é fazer, palavras são ações (AUSTIN, 1990), então os atos de fala estão alinhados com o dialogismo, pois a linguagem em uso prima pela ética. Desse modo, esta pesquisa volta-se para fundamentos teóricos da filosofia, linguística e educação, cujo objetivo é o de desenvolver uma reflexão mais aprofundada sobre o problema ético na educação a partir de fundamentos da Filosofia Clássica, da ética e suas possíveis relações na Filosofia Contemporânea.

Este trabalho divide-se em elementos teóricos, que nos permitam desenvolver este debate; em seguida aborda alguns problemas inerentes à ética na educação e, por fim, aponta possíveis relações entre ética e educação. 


\section{ELEMENTOS TEÓRICOS ACERCA DO PROBLEMA ÉTICO NA EDUCAÇÃO}

A discussão delimitada que tem como escopo elementos teóricos sobre o problema ético na educação está perpassada pela Filosofia, que de modo amplo diz-se aquilo "de que se ocupam os filósofos" (BOUFLEUER; NEITZEL, 2014, p. 3); bem como pela Educação, entendida como "o ponto em que decidimos se amamos o mundo o bastante para assumirmos a responsabilidade por ele e, com tal gesto, salvá-lo da ruína que seria inevitável não fosse a renovação e a vinda de novos e dos jovens" (ARENDT, 2013, p. 247). Conclui a filósofa contemporânea que a educação é o processo de inserção de novas gerações no mundo velho, isto é, a educação no ponto de vista da geração seguinte é sempre obsoleta e rente à destruição.

Sendo assim, a ética faz parte da Filosofia, que é uma área do conhecimento mais ampla, e está presente, por exemplo, na Educação, Economia e Política. Esta é fruto das relações entre as pessoas, contudo, independente e com objeto de estudo próprio, ocupando-se da relação íntima entre o agir do ser humano na perspectiva aristotélica, segundo o qual a perfeição de um ser se encontra no seu fim, a Ética teleológica, que a realização do ser humano é cumprir o fim para o qual ele existe.

A perspectiva clássica é duramente criticada na contemporaneidade devido ao seu caráter essencialista e antropológico por perguntar o que é o ser humano. Pergunta para a qual não há resposta, bem como não se responde à questão: qual é o fim ou perfeição de um ser humano? Segundo Vaz (1992) a respostas para essas perguntas elaboradas pela cultura clássica podem ser resumidas em duas, a saber: o ser humano como animal racional (zôon logikón), excelência na vida intelectual, e como animal político (zôon politikón), excelência na vida política.

Na Idade Média, a tradição cristã-medieval plasmou a concepção de que o ser humano seria, em sua essência, “a imagem e semelhança de Deus". Esse entendimento respondia à questão clássica, que perdura até os dias de hoje: "O que é o homem?"

René Descartes inaugura na modernidade uma nova resposta à pergunta "O que é o ser humano?". No início do século XVII, em sua compreensão racionalista, compreende o ser humano como ser pensante (res cogitans) e ser corpóreo (res extensa). Nessa perspectiva, o ser pensante tem o papel de melhor conhecer o mundo para dominá-lo; o ser corpóreo compreende o animal máquina. 
A ideia difundida pelo Iluminismo, no século XVIII, refere-se ao progresso da razão a ser alcançado mediante mudanças desenvolvidas, inicialmente na sociedade, pelo próprio ser humano. Identificamos uma antropologia, uma vez que o homem não é mais visto como naturalmente mau ou decaído de uma natureza sagrada. Na perspectiva antropológica do Iluminismo, cada ser humano é um ser único, com o seu valor, individualmente. Esse individualismo é apontado como característica desse período; contudo, o mais marcante é o caráter racional do ser humano.

Emmanuel Kant (2011) construiu duas críticas e forjou a sua matriz antropológica sobre a ética, a Crítica da razão pura e a Crítica da razão prática. Como dito, Kant considera centrais e necessárias questões que procuram responder as atitudes do ser humano, quando ele próprio se pergunta o que pode saber, o que deve fazer e o que lhe é permitido esperar. E a síntese das três primeiras é a questão: O que é o homem? Para Kant, a resposta desta última revela o homem que sabe, faz e espera ao tomar uma atitude em sua vida.

Tomando-se por base Hegel (1992) e em seguida Marx (2007) para falar do aspecto histórico da existência humana, apresentamos a pluralidade da antropologia contemporânea. Na perspectiva desses pensadores, a existência humana é vista pelo saber antropológico como relativa, passando a ser marcada pela história e cultura da qual faz parte. Para esses filósofos, e desde então, diversas respostas são dadas para a pergunta: “O que é o ser humano?”, isso porque são formuladas conforme abordagens, metodologias, condições históricas e culturais, inseridas no contexto. A partir dessas visões se fortalecem os estudos das ciências humanas, ao passo que ocorre a expansão universitária em fins do século XIX e consolidação do saber científico no início do século XX, o que favoreceu estudos com métodos de investigação específicos.

Marx investigou a razão ética, que se constitui uma superestrutura de legitimação (ideológica: ideias políticas, religiosas, morais, filosófica e política, estado de polícia, exército, leis e tribunais) e justificação daquilo que é determinado pela infraestrutura da base econômica da sociedade. Embora Marx não tenha construído um discurso direto sobre a ética, seu pensamento exerce uma forte influência sobre o pensamento ético, incluindo a ética na educação, isso porque faz críticas da sistematização da ética desde Platão até Hegel.

Em meados do século XX, o saber antropológico começa a se desvencilhar da Filosofia, passando a questionar o modo tradicional de se fazer o que foi denominado de Antropologia filosófica, isso porque estudos específicos de comunidades primitivas passaram 
a nortear os questionamentos da Antropologia, sendo uma delas de cunho ético, a saber, "qual deve ser a ação do ser humano diante do outro e do mundo?”.

Esse questionamento serve de base e perdura até hoje, desdobrando-se para o campo da Educação. Esta vista como processo de formação humana deve ser eminentemente ética. A ação de educar está colada à atitude ética. O problema ético na educação consiste em uma questão antropofilosófica pois a literatura dessas duas áreas de conhecimento construiu os seus discursos no decorrer do percurso histórico desde o pensamento grego.

Em a "Alegoria da caverna", texto que abre o Livro VII, de A república de Platão (1999), o objetivo é tratar da educação. Nesta alegoria a educação consiste no movimento em busca do aprendizado para a conhecer o Bem. Assim, o ato ético consiste na transformação do homem, isso porque o Bem é compreendido como Ser, que tem uma lógica, que possibilita a contemplação à luz da razão. A partir disso, o existir do ser humano consiste no exercício das virtudes, bem como a prática da justiça na cidade.

A prática da justiça tendo como o fim último o Bem. Ela também foi tema do pensamento cristão no medievo. A tradição cristã-medieval retoma a visão grega do Bem e da Virtude e a transpõe para um exercício interno do ser humano cuja força advém da divindade. Para a antropologia cristã "o homem é a imagem e semelhança de Deus"; por meio do divino o homem é interpelado a orientar a sua vida. O ato ético norteia-se pela obediência dos cânones do cristianismo, a educação cristã ensina que ser ético é agir conforme a fé cristã.

Esse entendimento muda com o advento do realismo moderno. A educação passa a ser vista como promoção da razão e não da iluminação divina. Descartes, como dito, buscou um fundamento indubitável para o saber teórico, sendo um conhecimento adquirido pela capacidade de raciocínio humano. Na razão repousa o fundamento ético, que é um desdobramento da verdade teórica, fruto do exercício intelectual. Contudo, enquanto o ser humano não alcança o fundamento último para o agir ético, Descartes (2001) orientou a busca pela "moral provisória", em seu livro Morale par provision, que ensina o agir na prática, no aqui e agora. O limite dessas páginas impossibilita o desenvolvimento dessa questão cartesiana devido a sua amplitude.

Faz-se necessário apresentar o pensamento de Emmanuel Kant, cuja teoria prima pela razão como ponto fundamental da moral. A questão central colocada pelo filósofo, na Crítica da razão prática é qual a possibilidade do Bem supremo. Para Kant, a razão prática constrói a ética da ação do homem. Se bem orientado pela razão, esta jamais o levaria à desordem ou ao mal, visto que o homem regido pela razão se dirige ao ato que culmina no bem comum. 
Quando o ser humano entende a lei moral, que é construída individualmente, mas com validade universal porque a razão exprime o que é o Bem, então ele faz o que gostaria que lhe retribuíssem, na mesma medida.

Apesar da simplificação que aqui fizemos ao apresentar elementos teóricos da ética levantados pelos pensadores mencionados, o que mais nos importa é o peso de suas críticas, sem desmerecer outros mestres e suas contribuições. Na medida do possível, elencamos aqueles que influenciaram o discurso ético posterior. Os esforços que se seguirão para demonstrar a construção ética a partir disso são no sentido de evidenciar uma linha de pensamento, a fim de delimitar o problema ético no uso da linguagem ordinária.

A ética é um saber construído na prática. Para Habermas (2013, p. 31) a filosofia é "o modo de refletir sobre o pensamento e zelar pelo lugar da racionalidade". A guardadora da razão eleva o ser ao agir com ética na vida, sobretudo quando envolve o uso da linguagem. A realidade está atrelada a esse saber, o ser humano busca respostas sobre os problemas em geral, incluindo os da educação, e a existência do ser educacional por meio da linguagem se dá pelo agir ético.

No ensino de Filosofia da Educação, por exemplo, a linguagem apresentada toma a forma do pensamento, cabe ao educador concentrar-se em vivências pedagógicas, práticas que envolvem o debate com ética e responsabilidade. Boufleuer e Fensterseifer (2010, p. 261) afirmaram que "a condição do educador se constitui como sujeito inserido na cultura, como quem tem uma intimidade e cumplicidade com ela". A esse educador é dada a possibilidade de se relacionar com saberes educacionais e de estabelecer uma relação ética com o saber cultural. Estudante e educador assumem compromissos com a formação humana que revelam suas capacidades intelectuais.

O educador que é capaz de filosofar (exercitar a sua prática com o movimento reflexão-ação-reflexão); com atitudes éticas é o responsável por abrir espaço para o estudante pensar situações-problemas, e em conjunto constroem o aprendizado. Nesse processo, ambos vivenciam o debate com mobilização mútua, engajamento de educador e estudante e vivências filosóficas no processo educacional.

A Filosofia da Educação quando trabalhada na formação docente, seja no currículo seja na vivência, contempla a ética e os problemas éticos na educação. O exercício de vivências que propiciam o aprimoramento do ensino-aprendizagem, bem como do ato de ser ético e de construir o ensino e a aprendizagem como partes do movimento intercambiável da busca pelo conhecimento compõe a base para o uso da linguagem com responsabilidade. Para 
tanto, a história da educação tem revelado mudanças no comportamento de educadores e estudantes no processo de ensino-aprendizagem.

\section{UMA REFLEXÃO HISTÓRICO-PEDAGÓGICA}

Estamos passando por um momento que exige muita reflexão quanto à educação, e o tema em questão propõe rever alguns aspectos para o engrandecimento do ensinoaprendizagem. Os estudantes buscam um novo tipo de ensinamento, e o educador será o mediador que procurará despertar neles o interesse para o conhecimento. O educador irá propiciar esse tipo de aproximação e o encanto pela busca do aprendizado. O que se percebe, em geral, é um desinteresse tamanho em estar em sala de aula.

É interessante ressaltar que os meios educacionais através de seus educadores e todo o corpo técnico vêm procurando a todo o momento inovar com métodos e técnicas para que haja uma maior interação entre espaço educacional e sociedade. As famílias oriundas desse universo chamado sociedade, que por vezes já se encontra deteriorada pela discórdia generalizada no caos social e, sobretudo, pela falta de emprego, acabam por propiciar um problema maior para o processo educacional. E isso interfere no desempenho dos processos educacionais. Aliado a isso, o indivíduo passa a se revoltar contra tudo e contra todos, numa forma de revelar o seu descontentamento com a sociedade na qual vive.

O ser humano, nesse contexto em que vivemos, parece ter perdido o encanto pelo saber. Chama a atenção quando se reporta ao contexto, pois Austin priorizou o uso da linguagem enquanto ação e atribuiu um importante valor ao uso da linguagem dentro de um espaço social bem definido. Para tanto, é a linguagem que nos permite produzir conhecimento, gerando uma ação de reciprocidade entre os sujeitos falantes que elaboram o saber, este que está sendo constituído ao passo que se vai argumentando.

O processo educacional, fenômeno este que passa a ter muita importância devido ao fato de o mercado exigir uma boa qualificação nos dias de hoje, exige do estudante e do educador na mesma medida.

Com efeito, percebe-se que esta discussão parece passar despercebida por parte daqueles que deveriam dar sustentáculo para uma verdadeira educação de qualidade, promovendo aquisição de saberes mais qualificados com linguagens mais acessíveis e melhores condições de trabalho. E para que de fato isso aconteça torna-se necessária uma aproximação maior com os gestores. A educação tal como está concebida passa a ser vista 
como algo que não tem muita importância para o estudante, e aliado a isso também pode-se perceber que esse fenômeno desencadeia fatores relevantes como, por exemplo, a falta de educadores, de bons salários, de uma boa formação, de salas de aulas minimamente adequadas, aliado à precariedade do ambiente escolar no que tange à sua estrutura física. Os educadores estão sobrecarregados com afazeres e se viram em dois, em três para melhorar o seu salário e para dar uma vida melhor e mais digna para a sua família (BORDIEU, 1983).

Há um abismo que precisa ser superado no que tange à educação e à produção de conhecimento, e neste ponto entra o processo ético, envolvendo o campo educacional e o campo familiar. A família deve ser de uma maneira ou outra incentivada para que participe mais da formação de suas crianças de hoje, que serão os profissionais do amanhã. O estudante sente a falta dos seus pais no ambiente escolar. Muitos pais, embora tomem conhecimento dos conflitos inerentes à escola, nem sequer comparecem quando são chamados. Parece que delegaram aos educadores, além do papel de educador do ensino, o papel também de educador doméstico, no que tange à esfera familiar. Escola e Família usam linguagens específicas de cada contexto. Embora haja pontos de contato, o uso da linguagem dos pais difere da linguagem instrucional usada pelo educador, por exemplo.

O que deveria ser papel da família ou dentro do ambiente privado se reporta para o ambiente escolar. E tudo isso acaba gerando conflitos, pois nem sempre os educadores estarão propensos a dar esses encaminhamentos no que concerne à educação familiar. Existe por parte do educador toda uma preocupação com a sala de aula e seus afazeres e com suas respectivas famílias. Saviani aponta em seu livro Escola e democracia elementos para melhor entender o processo educacional e de formação.

Num primeiro grupo, temos aquelas teorias que entendem ser a educação um instrumento de equalização social, portanto, de superação da marginalidade. Num segundo grupo, estão as teorias que entendem ser a educação um instrumento de discriminação social, logo um fator de marginalização. (SAVIANI, 1985, p. 7).

Saviani faz referência a dois grupos distintos, em ambos há o poder ideológico de intervir no processo de formação. O que chama muito atenção em Saviani é a marginalização e a violência simbólica que expõem o ser humano a todo o momento, através da mídia e jornais, que de certa maneira molda o indivíduo de acordo com os interesses do Estado. “A violência simbólica se manifesta de diversas formas: a formação da opinião pública através 
dos meios de comunicação de massa, jornais etc.; a pregação religiosa; a atividade artística e literária; a propaganda e a moda; a educação e a família." (SAVIANI, 1985, p. 23).

Percebe-se que há um distanciamento entre o equilíbrio perfeito ou sociedade igualitária. Os estudantes, filhos de classes oprimidas, parece que já nascem e são em outras palavras controlados pela figura do Estado através do poder ideológico que possui. Cabe salientar que o processo educacional busca o processo de equacionar e aproximar as pessoas em sociedade (SAVIANI, 1985).

Entender essa sociedade capitalista na qual vivemos talvez não seja tão difícil; difícil seria equacionar esse antagonismo de classes. Ao que parece, essa dicotomia tende a se prolongar por muito tempo. Talvez seja possível reverter o processo de maneira gradativa buscando nas fontes elementares que contribuem para o surgimento dessa divisão e, a partir delas, tentar ao menos em parte equacionar em termos de igualdade. E na medida do possível criar uma aproximação entre educação e Estado e fazer com que tenham papéis importantes na consolidação das leis e para fortalecimento do processo igualitário (MARX, 2007).

Essa tentativa de equacionar tal fenômeno de forma a erradicar o problema não é uma tarefa simples, mas nada impede de procurarmos melhoras nos relacionamentos entre educadores e estudantes por meio do uso da linguagem, assim como no ambiente familiar.

Transformar os espaços em ambientes harmoniosos, cada um sentindo-se empoderado para vivenciar experiências em que o educador se anime a propiciar aos estudantes meios de debates, diálogos e resolução de problemas, assim como os estudantes se engajem nas propostas pedagógicas. Isso inclui, obviamente, ambientes domésticos menos conflituosos.

Assim sendo, apesar dos sérios problemas e conflitos relacionados ao processo ensinoaprendizado no processo educacional, é possível um enfrentamento com intuito de buscar elementos para transformar a sociedade, a escola tendo a sua função humana, social e cultural, cumprindo o seu verdadeiro papel, recuperando o seu status educacional. Cabe, portanto, aos educadores e à sociedade como um todo esforços concentrados objetivando soluções e a amenização dos problemas existentes no meio escolar. Em função da amplitude das dificuldades encontradas, faz-se necessário que os profissionais da área de educação se mantenham atualizados, preparados e bem qualificados para enfrentar as dificuldades que possam surgir no ambiente escolar. Afinal, uma escola de qualidade é constituída por toda a sociedade nas relações entre sujeitos. 


\section{PENSANDO O PROBLEMA EDUCAÇÃO E O USO DA LINGUAGEM}

Pensar a educação é de suma importância, vendo-a com o viés do discurso e da linguagem em uso, foco pouco comum na literatura. Com efeito, a linguagem em uso constitui-se por si mesma um obstáculo a ser superado, haja vista que para produção de conhecimento dispomos de vários meios, sejam eles por instrumento no mundo tecnológico, como computadores auxiliares no processo de aprendizagem, bem como pelas leituras e formas verbais e não verbais da linguagem (BAKHTIN, 1981).

Nessa linha de raciocínio destaca-se a linguagem, pois ela permite transmitir conhecimento. Como bem frisa Austin (1990), ao trabalhar o problema da linguagem na abordagem da Pragmática, a linguagem em uso consiste em um fio condutor que permite produzir e transmitir conhecimentos.

Ocorre que surgem nessas transmissões de conhecimento dimensões nos atos de fala do educador que usa a linguagem para proferir atos de fala. Essas dimensões, embora não seja o intento trabalhá-las aqui, formam o pano de fundo para esta reflexão. Para que o educador pergunte a si mesmo se de fato os elementos constituintes dos atos de fala estão se efetivando, ele realiza atos ilocucionários, o dizer cuja produção de efeito se realiza ao perguntar, prometer e doar, por exemplo. Nesse caso a intenção do dizer é compreendida no ato de fala, tal qual pretendia o falante (AUSTIN, 1990).

A linguagem, portanto, afeta a transmissão do conhecimento, isso porque nem sempre o dito é compreendido tal qual a intenção daquele que profere uma sentença. O educador, fazendo um bom uso da linguagem, tem nas mãos uma ferramenta que possibilita o atingimento dos objetivos.

Indagamo-nos como educadores: qual linguagem deverá ser usada? Para tal indagação se tomará como base os escritos de Austin em que devemos entender o contexto e nos adequar a ele para que o processo como um todo seja efetivado. Entendendo o contexto será possível ajustar conhecimento e ato de fala, assim, dizer é transmitir o conteúdo dentro da realidade do estudante e, por conseguinte, realizar atos ilocucionários (AUSTIN, 1990).

Para esse propósito de transformação da realidade iniciando-se por meio da linguagem em uso, é fundamental que educador e estudante adotem uma postura ética. Porque sempre se pergunta os fins que se quer atingir como bem frisa Aristóteles em sua obra Ética a Nicômaco, estabelecendo as virtudes que o homem deve buscar. O fim a ser buscado, ou aqui em especial debatendo educação, procurar traçar metas acerca do que queremos. Esta reflexão acerca dos meios e fins para alcançá-lo remete ao campo da ética e da moral dado a ela estar 
se referindo ao ser humano. E se aspiramos a um fim último para o saber, estamos pensando eticamente. A reflexão aqui proposta visa a estabelecer um parâmetro para se pensar o ser humano inserido no mundo cheio de indagações. Estas indagações mesmo que pontuais fazem parte dos questionamentos enfrentados nos dias atuais.

\section{ALGUNS PROBLEMAS ÉTICOS NA EDUCAÇÃO}

No tocante à ética como conteúdo específico da Filosofia e essencial da formação humanista dos profissionais em educação, encontramos no seio dessa área de estudo uma realidade cada vez mais midiatizada por conta das Tecnologias de Informação e Comunicação (TICs). Importante destacar que as tecnologias são vistas de modo positivo desde que exploradas, um tipo de inovação. Tempos exigentes, com estudantes cada vez mais embevecidos pelas tecnologias, requerem atitudes adequadas para a realização de encontros atrativos que sejam empolgantes para o educador e favoreçam o ato de filosofar.

Um problema ético que perpassa por essa realidade educacional é o fato de que educadores e estudantes, em tal cenário, não têm espaço para uma abordagem conteudista da Filosofia, com aulas expositivas e assuntos distantes da vida; é preciso filosofar, este é o nosso posicionamento. Se nas aulas de Filosofia da Educação há espaço para a atitude filosófica, quando da ação docente, este saberá abrir espaço para o estudante filosofar. Cumpre-nos endossar o entendimento de que o ensino consiste na abordagem de textos da tradição filosófica, pensamentos e biografias de filósofos, desde que seja possível fazer ligações com os problemas vivenciados pelos envolvidos no processo. Não se propõe, aqui, sob nenhuma hipótese, subtrair conhecimentos da tradição ocidental, trata-se de adequar o ensino de Filosofia às questões que educador e estudante vivenciam e conseguem perceber a concretude da abstração do texto de um filósofo, que pode ter sido escrito há dois mil e seiscentos anos e, ainda assim, tem fundamento e propicia o debate e a reflexão sobre o tema em realce.

Oportunizar ao estudante e sua turma experiências que levam à compreensão das filosofias é um desafio enfrentado pelo educador, uma vez que são momentos medidos, predominantemente, pela linguagem verbal. Isso porque as aulas de Filosofia, independentemente do nível educacional, são peculiares, a essência dos pensamentos e legados deixados pela tradição compõe o conteúdo, mas as aulas não podem se limitar a essas teorias. Cabe ao educador dinamizar o processo de ensino-aprendizagem com o uso da 
linguagem para deixar claro que são filosofias, pensamentos e teorias, que em maioria divergem, mas coexistem justamente pela diversidade discursiva. A ética da linguagem evidencia-se pelo dizer, que é fazer e pelas palavras-atos, isto é, dizer é fazer, e palavra é ação. Quando digo "eu prometo", não estou apenas verbalizando uma sentença, estou exercendo a ética, que é algo que requer certo esforço, por estar diretamente ligada à prática da capacidade e da responsabilidade da pessoa.

O discurso transforma a realidade porque dizer é fazer coisas com palavras, e ao fazer o sujeito se posiciona no mundo. O educador apresenta uma pluralidade de conhecimentos e ideias que suscitam em todos que estão participando daquele momento interpretações e criatividade sobre um ou outro tema, sendo que o processo não tem uma única resposta pronta ou apresenta perspectivas que conformam a autonomia do sujeito. Este, por sua vez, constrói o seu conhecimento com ética e torna-se muito mais consciente e eficaz além da consolidação de uma sociedade mais justa.

Cada um torna-se artífice de sua realidade, responsável pela construção do conhecimento com ética. Se a ética é a ciência normativa que conduz ideais promissores dentro da comunidade, uma vez que o ser humano é um animal social, seria inútil compreendê-la como ciência para indivíduos e juntos construírem uma sociedade mais justa. A elaboração do discurso torna-se possível quando o ser humano tem conteúdo. Para tanto, compreender que se pode transformar o mundo do qual fazemos parte a partir de nossas atitudes consiste em estabelecer uma rede de relações entre os sujeitos, na vida educacional e fora deste espaço, na sociedade. O educador é aquele que inicia esse processo de aprendizado, ensinando, usando uma linguagem ética; cabe ao estudante contribuir com esse movimento no cotidiano da realidade educacional. $\mathrm{Na}$ prática deve haver um relacionamento de confiabilidade. Durante as vivências cada pessoa tem sua compreensão com base nos elementos em debate e por meio do discurso sente aberto para o filosofar.

O desafio do ato de ensinar encontra-se, entre outras perspectivas, na capacidade de pensar a própria vida, o mundo em que se vive e a sociedade com suas questões, estabelecendo relações com teorias, textos e reflexões éticas. O texto filosófico deve ser lido e problematizado, com referências à condição humana e com o cuidado de respeitar o contexto.

As situações-problemas nos âmbitos local, regional, nacional e internacional servem de base para educador e estudantes pensarem e filosofarem. Na realidade, não se espera como resultado a solução definitiva dos problemas, muitos complexos e de difícil entendimento. $\mathrm{O}$ que interessa nessa esfera de uso da linguagem é o exercício do debate que constrói 
posicionamentos de sujeitos que vivem o tempo presente. Dos vários assuntos, destacamos: política (municipal, estadual ou federal), falta de ética, economia, degradação do meio ambiente (local), ética nas relações digitais (regional, nacional e internacional), e terrorismo (mundial).

Cada educador preocupa-se em ministrar aulas com linguagem acessível e de forma dinâmica, de modo que envolva o estudante e favoreça o processo de ensino-aprendizagem. $\mathrm{O}$ desafio é manter cada um com o sentimento de pertencimento e atento ao que o educador diz, ou melhor, faz em sala de aula. Gallo (2012) afirma que isso ocorre quando o educador deposita no estudante confiança, demonstra o quanto o considera competente para filosofar nos aspectos cognitivo, emocional, intelectual e de interação com a turma. Segundo Cerletti (2009), quando se cria uma comunidade de investigação nas aulas de Filosofia, ou outro componente curricular, ocorre o engajamento dos que estão envolvidos no processo.

Aulas com propostas investigativas não permitem improvisação, requerem do educador linguagem adequada, planejamento, preparação e elaboração de sequência didática. Esses passos abrem o espaço para as vivências em sala de aula. A partir disso, acontece a criatividade do ser humano e de suas ideias. Favorecer vivências filosóficas consiste em organizar previamente todo o roteiro, porque "é preciso tomar o devido cuidado para não cair no outro extremo caracterizado por um espontaneísmo pedagógico", alerta Horn (2009, p. 87).

A barreira do uso ético da linguagem por parte de educador e do estudante, este em igual grau que aquele, apresenta-se como desafio evidente no contexto educacional. Uma proposta é trazer da Filosofia textos em diversos gêneros do discurso. Conforme o texto Gênero do discurso, de Bakhtin (2006), são gêneros de discurso as diversas formas de texto que podem ser escritos e orais, por exemplo: cartas (epístolas), diálogos, argumentações (lógicas e aforismos). Nesse contexto, gêneros do discurso consistem em textos usados no processo de produção de sentido, discurso e manifestação social, cuja plasticidade se adequa ao contexto. A ética no uso da linguagem ocorre por meio do gênero do discurso nas dimensões histórica e ideológica. A elaboração do texto no dizer, portanto, imprescindível no processo de ensino-aprendizagem, é o ponto em que se pode integrar a aula de Filosofia e de Língua Portuguesa. Essas duas áreas estão interligadas, e o uso da língua está agregado à atividade filosófica. Conteúdo é, na verdade, o ponto de partida para o questionado e serve de pretexto para os debates, orais ou escritos, bem como para as construções de sentido. Filósofos e filósofas publicam seus textos discutindo questões atuais; apenas para citar, alguns falam sobre a historiografia da Filosofia Brasileira (CHAUÍ, 2000), problema de gênero 
(BUTLER, 2003), da estética à política (AGAMBEN, 2005), e ensino de Filosofia Contemporânea no Brasil (GALLO, 2012). Falar desses e de outros textos são ações que contribuem para os debates sociais e políticos.

Na filosofia bakhtiniana da linguagem encontra-se o pensamento de que a linguagem é híbrida, ou seja, a expressão verbo-visual e iconográfica contém várias vozes de áreas aparentemente diversas e pensamentos nem sempre uníssonos, sendo essa heterogeneidade o cerne do filosofar. Portanto, as atividades do ensinar a filosofar não podem nem devem limitar-se ao ato de expressar, por meio da linguagem do educador e estudante, os pensadores do passado, biografias e teorias para aplicar a ideia ao presente. Estudar filósofos do passado é interessante desde que vistos nos contextos em que viveram. De sorte que não se pode furtar o estudo de pensadoras e pensadores do tempo presente, suas ideias partem de questões contemporâneas e cada modus operandi deve ser a primazia da singularidade para a construção de conhecimento do sujeito.

Da realidade educacional destaca-se um problema para o qual dirigimos agora o nosso foco, a saber, a formação do educador por meio da ética e sua problematização na Educação. Muitas vezes são ministrados conteúdos da Filosofia destacando a história e a biografia dos filósofos. Esse tipo de abordagem deixa no aprendizado dos educadores alguns nomes que inspiram a intelectualidade, como Sócrates, Platão e Aristóteles da Idade Antiga; Agostinho e Tomás de Aquino, na Idade Média; Kant e Hegel, na Idade Moderna; e Austin, Wittgenstein e Foucault na contemporaneidade.

Desse modelo destacam-se dois problemas: o primeiro é o fato de não dar espaço para o ato de pensar a ética, e este movimento tornar-se o filosofar; e o segundo, de não contemplar nenhuma pensadora, ou melhor, filósofa. Da Grécia Antiga preserva-se uma tendência androcêntrica. O desafio do educador é retirar essa visão de que a Filosofia é algo que está no passado e é predominantemente masculina, sendo algo muito distante da realidade atual.

Uma perspectiva que permite repensar o ato de ensinar, abandonando o conteúdo para memorização, uma vez que não é este o foco da Filosofia, é ir ao princípio da aprendizagem no dia a dia educacional. Nesse espaço há um ator principal, o discente, que embora seja assim, a aprendizagem é estimulada pelo educador, ou na docência-discência, "dodiscência" (FREIRE, 1996, p. 15). Para Freire (p. 32), "não existe docência sem o discente, ambos estão entrelaçados no ser e no fazer pedagógico".

A reflexão do ser humano, como educador, acerca do ambiente acadêmico, necessita de vivências que permitam formações e contato com textos, ensinamentos e debates 
filosóficos. Isso porque é preciso ir ao princípio da aprendizagem, que para Delors (1998) consiste em aprender a conhecer: aquisição dos instrumentos de conhecimento para desenvolver o raciocínio lógico, a capacidade de compreensão, o pensamento dedutivo e intuitivo e a memória; aprender a fazer: aplicar a prática aos conhecimentos teóricos, sabendo se comunicar através de diferentes linguagens, interpretar e selecionar informações; aprender a conviver: tomar atitudes que são a primazia da consciência reconhecendo valores e ações contra o preconceito e as rivalidades; e aprender a ser: vivenciada desde que os outros três aprenderes estejam consolidados, estamos sempre aprendendo a ser, porque o desenvolvimento do indivíduo em espírito e corpo é um processo que requer sensibilidade, sentido estético e responsabilidade. O ser ético é aquele que vive com liberdade, executa a cidadania e tem objetivo para viver.

\section{A IMPORTÂNCIA DA FILOSOFIA NO MEIO EDUCACIONAL}

O que se percebe na sociedade em que vivemos é uma educação que prepara para o mercado de trabalho. E isso em certo sentido acaba interferindo na capacidade de reflexão do ser humano frente aos desafios do mundo, os quais não são mecânicos e simplórios, são dinâmicos e complexos. Dentre os conhecimentos, o que trabalha a capacidade de problematização é a Filosofia. Esta possui os elementos fundamentais para a realização do processo reflexivo que o ser humano é capaz de fazer e, usando a linguagem verbal, de transmitir ao outro.

A reflexão filosófica contribui para uma transição entre épocas, de modo que o passado seja aproximado com o presente e serve de base para a ressignificação da vida. A ideia de que a filosofia só se reporta ao passado e se esquece do presente não procede. Na realidade, a reflexão filosófica propicia ao sujeito a capacidade de se preocupar, pensar e esclarecer as inquietações impostas pela vida, buscando apaziguar os conflitos. O desenvolvimento reflexivo oriundo do pensamento filosófico tem por fim despertar o interesse pelo novo.

Assim, no processo de educação há de se enfatizar muito a linguagem, pois ela está sempre presente propiciando a transmissão do saber. Se pensarmos a linguagem e a forma que a usamos em nosso dia a dia, perceberemos que desempenhamos ações ao e por dizer algo; em que dizer algo estamos realizando atos, provocando efeitos para que o sujeito construa conhecimento (AUSTIN, 1990). 
E nesse viés a linguagem, se bem aplicada em conformidade com o contexto, tem por fim produzir esse efeito positivo no outro. Se a linguagem é uma ação, ela deve ser realizadora de modo que permita que de fato sejamos construtores de conhecimento e ao mesmo tempo mediadores dele.

Os debates no cenário atual no que se refere à educação devem ser primados por um saber reflexivo, em que o sujeito esteja inserido no meio do processo, fazendo com que seja parte integrante do processo ensino-aprendizagem. Fazer esse resgate é de suma importância, pois é possível fazer indagações que buscam saber o que é o ser humano, a sua finitude e seu agir no mundo, isso culmina em um processo ético.

Esta talvez seja uma resposta que de antemão não temos, mas com debates e reflexões críticas neste universo e com o apoio de base filosófica, seja clássica, moderna ou contemporânea é possível refletir e buscar alternativas que amenizem os problemas na educação e na vida. $\mathrm{O}$ que se tem é um apelo por uma nova forma de saber, de transmitir conhecimento e de se pensar frente às grandes tecnologias criadas, sem perder de vista reflexões propiciadas pelos pensadores.

A Filosofia nos tira do campo do eu acho e nos coloca a pergunta de como de fato conhecemos. Devemos nos livrar do campo das opiniões e trilhar para um conhecimento de forma mais segura, afastarmos do caminho das opiniões (doxa), que não leva a nada, e nos enveredar para o caminho da alétheia (verdade). A filosofia vem para nos tirar da zona de conforto e nos propicia pensar a nossa finitude enquanto sujeito e a nossa construção em sociedade amparada pelos princípios da moral da Ética que regulamenta o nosso agir. A educação tem esse papel, consiste na ação de educar.

O problema da educação precisa ser encarado como ação de produção de saber e de acessibilidade a todos. Para o nosso século o debate se abre para o acesso ao saber, e a forma de como fazer elos, sem perder as nossas raízes filosóficas. Aqui não se trata de descartar o novo em detrimento do antigo, e sim realocá-lo em acordo com a reflexão sem perder de vista as nossas bases essenciais dos verdadeiros filósofos.

\section{CONSIDERAÇÕES FINAIS}

Nesta pesquisa apresentamos o quadro da ética como elemento problematizador da Educação, apresentamos alguns problemas e acompanhamos o entendimento de algumas perspectivas, sendo a principal a formação filosófica. De modo mais específico, nos aliamos 
àqueles que são defensores dos filósofos educadores e estudantes e que pensam a prática com ética.

A linguagem tida como mediação para o processo de ensino-aprendizagem em vivências envolve o educador-filósofo e o estudante aberto ao filosofar. Essas vivências são construídas conjuntamente, das quais cada um torna-se empoderado para tirar suas próprias conclusões e assumir seus pontos de vista.

$\mathrm{O}$ ato de filosofar é uma experiência ética, isto é, uma aprendizagem que se adquire ao passo que se vai fazendo. Contudo, não prescinde da habilidade de memorização nem de aprendizado do conteúdo, porque o domínio do assunto é o que dá material para se pensar sobre algo, refletir, questionar e absorver sobre o tema.

Nesta pesquisa chega-se ao entendimento, não definitivo, de que a formação do educador requer estudos de Filosofia, de ideias que se adequam às discussões vivenciadas por cada grupo, de experiências que envolvem debates sobre a ética da vida, sem se restringir a esse contexto e abrindo-se para debates do que ocorre no Brasil e no mundo, desde que com bases em leituras de intelectuais da atualidade. Ideias de filósofos da tradição são contempladas na formação do ser humano, desde que seja possível estabelecer ligações com assuntos que significam e são do interesse do grupo de pessoas envolvidas nesse processo formativo, que é feito por meio do questionamento.

A Ética é uma disciplina que, se ministrada por educadores capazes de filosofar, tornase um espaço aberto para a reflexão sobre questões, permitindo a cada um tirar suas próprias conclusões, desde que estas tenham por base os múltiplos caminhos apresentados pelos fundamentos estudados. Os problemas que mobilizaram pensadores e pensadoras da atualidade são adequados para o começo da conversa porque envolvem questões que atingem, direta ou indiretamente, os grupos que compõem o contexto educacional do tempo presente, por exemplo, a questão do meio ambiente, da educação e da política, apenas para citar alguns.

No processo de ensino-aprendizagem dos dias atuais é necessário inserir as Tecnologias de Informação e Comunicação (TICs). O uso da tecnologia é uma perspectiva que atualiza a aula de Filosofia e adequa-se à realidade tanto de educador como de estudante do século XXI.

Dos desafios para o ensino da ética e dos problemas educacionais, citamos: a sala de aula com estudantes que nem sempre estão abertos para o filosofar, obstaculizando a proposta de vivências filosóficas; o ato de ensinar filosofando por parte do educador, devido à postura passiva do estudante, não todos, mas ainda persiste atualmente; a dificuldade de se chegar a 
um consenso quando a proposta do educador é eleger um tema de interesse para servir de base para o ato de filosofar, e de experimentar, ou seja, de vivenciar os debates para atingir a compreensão das filosofias; educadores e estudantes enfrentam a dificuldade de pensar questões que envolvem as suas próprias vidas.

Na perspectiva de valorizar a problematização, o ponto primordial é oportunizar tanto educador como estudante o ato do pensar autônomo e voltado à transformação do ambiente convencional em espaços interativos e abertos que permitam criações de alternativas inovadoras para o contexto. $\mathrm{O}$ ato de ensinar é por si mesmo um desafio, que encontra perspectivas para as pessoas, pois cada um vive estabelecendo as relações entre teoria e prática por meio de textos filosóficos lidos e problematizados dentro de um contexto bem definido. Esse entendimento acompanha a proposta de Gallo (2012), cuja essência encontra-se na capacidade que cada educador tem ao depositar confiança no ato de pensar do estudante.

A linguagem em uso não pode permanecer como obstáculo no processo de ensinoaprendizagem, porque por meio dela se constrói o filosofar. Realiza-se ação com o discurso ao se elaborar gêneros discursivos, uma vez que é escrevendo cartas, notícias, artigos e palestrando, dialogando e prometendo que acontece o filosofar, não como algo distante da realidade e sim como parte da realidade.

\section{REFERÊNCIAS}

ARENDT, Hannah. A crise na educação: entre o passado e o futuro. São Paulo: Perspectiva, 2013.

ARISTÓTELES. Ética a Nicômaco. Tradução de Leonel Vallandro e Gerd Bornheim, da versão inglesa de W. D. Ross. São Paulo: Nova Cultural, 1987.

ARISTÓTELES. Metafísica: livro I e II. São Paulo: Abril Cultural, 1984.

AUSTIN, John Langshaw. Quando dizer é fazer: palavras e ação. Tradução de Danilo Marcondes de Souza Filho. Porto Alegre: Artes Médicas; 1990.

BAKHTIN, M. Os gêneros do discurso. In: BAKHTIN, Mikhail. In: Estética da criação verbal. Trad. Paulo Bezerra. 4 ed. São Paulo: Martins Fontes, 2006b, p. 261-306 [19521953].

BAKHTIN, Mikhail Mikhailovich. Problemas da poética de Dostoiévski. Tradução Paulo Bezerra. 4. ed. Rio de Janeiro: Forense Universitária, 2008.

BAKHTIN, M. Problemas da poética de Dostoiévski. Trad. Paulo Bezerra. Rio de Janeiro: Forense-Universitária, 1981. 
BORDIEU, Pierre. Sociologia. São Paulo: Ática, 1983.

BOUFLEUER, José Pedro; FENSTERSEIFER, Paulo Evaldo. A reconfiguração da dialética pedagógica com vistas a uma formação emancipadora. Currículo sem Fronteiras, v. 10, n. 2, p. 259-267, 2010. Disponível em: http://132.248.9.34/hevila/CurruculosemFronteiras/2010. Acesso em: 24 jun. 2019.

BOUFLEUER, José Pedro; NEITZEL, Odair. O ensino da filosofia: um possível modo de situá-lo no currículo da educação básica. X ANPEDSUL/UDESC, 2014. Disponível em:13<http://xanpedsul.faed.udesc.br/arq_pdf/579-0.pdF>. Aceso em: 03 AGO 2019.

BUTLER, J. Problemas de gênero: feminismo e subversão da identidade. Tradução de Renato Aguiar. Rio de janeiro: Civilização Brasileira, 2003.

CERLETTI, A. O ensino de filosofia como problema filosófico. Belo Horizonte: Autêntica, 2009.

CHAUÍ, Marilena. Convite à filosofia. São Paulo: Ática, 2000.

DELORS, Jacques. Educação: um tesouro a descobrir. Relatório para a UNESCO da Comissão Internacional sobre Educação para o século XXI. São Paulo: Cortez, 1998.

DESCARTES, R. MORALE PAR PROVISION. In: DESCARTES. Discurso do método. Tradução: Maria Ermantina Galvão. Martins Fontes: São Paulo: 2001.

FREIRE, P. Pedagogia da autonomia: saberes necessários à prática educativa. São Paulo: Paz e Terra, 1996.

GALLO, Silvio. Governabilidade democrática e ensino de filosofia no Brasil contemporâneo. Caderno de Pesquisa [online]. 2012, v. 42, n. 145, p. 48-65. Disponível em: http://dx.doi.org/10.1590/S0100-15742012000100005. Acesso em: 24 jun. 2019.

HABERMAS, Jürgen. Consciência moral e agir comunicativo. Rio de Janeiro: Tempo Brasileiro, 2013.

HEGEL, G. W. F.. Fenomenologia do espírito. 2 v. Petrópolis: Vozes, 1992.

HORN, G. B. Ensinar filosofia: pressupostos teóricos e metodológicos. Ijuí: UNIJUİ, 2009.

KANT, Immanuel. Crítica da Razão Prática. Tradução de Valério Rohden. 3. ed. São Paulo: WMF Martins Fontes, 2011.

MARX, K.; ENGELS, F. A Ideologia alemã: crítica da mais recente filosofia alemã em seus representantes Feuerbach, B. Bauer e Stirner, e do socialismo alemão em seus diferentes profetas (1845-1846). São Paulo: Boitempo, 2007.

PLATÃO. A República. São Paulo: Nova Cultural, 1999. 
SAVIANI, Dermeval. Escola e democracia: teoria da educação, curvatura da vara, onze teses sobre educação e política. 6. ed. São Paulo: Cortez: Autores Associados, 1985.

SAVIANI, Dermeval. Pedagogia histórico-crítica: primeiras aproximações. 9. ed. rev. e ampl. Campinas, Autores Associados, 2005.

VAZ, H. C. L. Antropologia filosófica I. São Paulo: Loyola, 1991.

VAZ, H. C. L. Antropologia filosófica II. São Paulo: Loyola, 1992. 